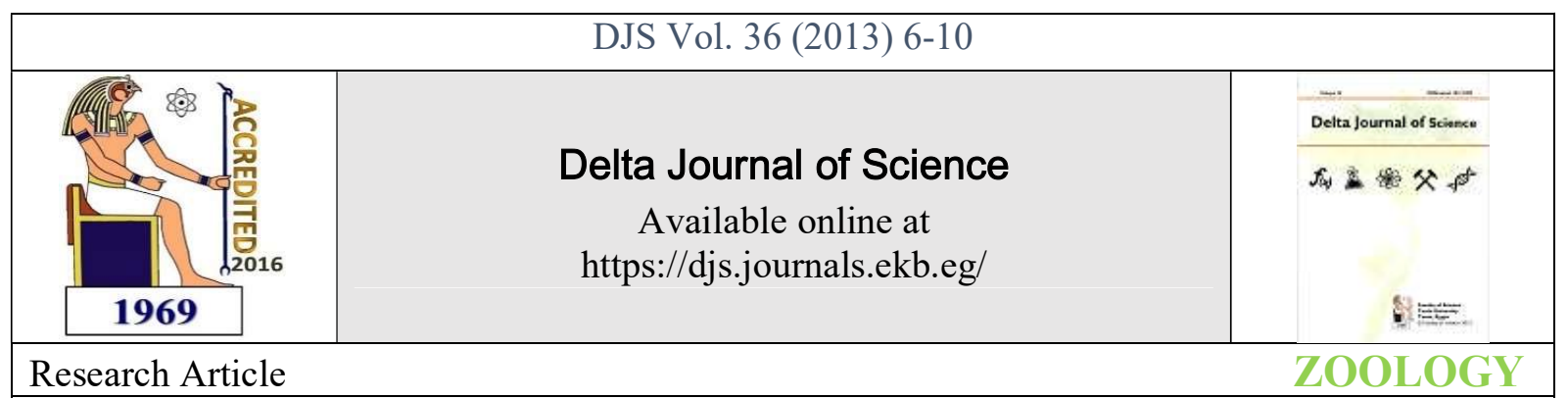

\title{
U1tramorphological studies on the lingual papillae of Rabbit (Oryctolagus cuniculus) in relation to its feeding habits
}

\author{
Gamal Ali Mohammed \\ Departments of Zoology, Faculty of Science, Zagazig \\ University, Egypt
}

Key words: Rabbit, Tongue, Papillae, Light and Scanning Microscope

\begin{abstract}
The distribution and structure of the lingual papillae on rabbit tongue were studied in relation to its feeding habits by means of light and scanning electron microscopy. The tongue of rabbit is of about $5 \mathrm{~cm}$ in length and $9 \mathrm{~mm}$ in width. The dorsal surface of the tongue is differentiated into four regions according to the nature of papillae; apex, body, lingual torus (intermolar prominence) and root. On the surface of the apex and body of the tongue there are four main types of papillae: filiform, fungiform, vallate and foliate papillae. The filiform one can be differentiated morphologically into five sub types of variable size and shape according to their location. Fungiform papillae are numerous on the anterior part of the tongue. They are elliptical or circular in shape and embedded in between filiform ones. In this region both filiform and fungiform are devoid of taste buds indicating their mechanoreceptive function. Two oval vallate papillae with numerous taste buds are situated on the side wall of the tongue root, elucidating their chemoreceptive role. A Pair of patches having well developed foliate papillae is observed in the latero-posterior part of the tongue. Each is oval in shape and has several parallel papillae lacking taste buds and may separate by shallow grooves. Histological observation indicates keratinization of the dorsal surface of the tongue with variable degrees.
\end{abstract}

\section{INTRODUCTION}

The fact that rabbit has adapted to herbivorous diet with modified teeth (Davis, 1964) suggested that the tongue might also exhibit modifications related to its specialized diet. In primates, some carnivorous and rodents, the tongue has lost its importance in the function of food prehension, since these animals use their paws to bring food to the mouth (Iwasaki, 2002). The feeding mechanism is clearly an important factor that determines the success of vertebrates tongue to the environment (Roth and Wake, 1989).

Early studies on the morphology of the tongue surface carried by Sonntag (1923) described the shape, situation and types of lingual papillae in different mammalian species. Later on, there are numerous studies of the tongue papillae by means of SEM in rat (Iida et al., 1985), cat (Chamorro et al., 1987), horse and cow ( Paz et al., 1988), dog ( Holland et al., 1989), and monkey (Iwasaki et al., 1992). It was found that the surface of the mammalian tongue has a papillary system with two specific functions: gustatory and mechanical. The gustatory papillae show taste buds and pores, whereas the mechanical papillae play a role in tongue surface protection, food prehension mastication and swallowing (Chamorro et al., 1994)

Some what recently, (Emura et al. 2000 a\&b and Emura et al. 2004) studied the morphology of the lingual surface in carnivores with the scanning electron microscope. The general description of the lingual papillae made by koeing and Liebig (2001) revealed different variations in morphology and distribution of papillae on dorsal lingual surface among different animal species.

The present study was performed to investigate the histological and morphological differences of the tongue papillae in the domestic rabbits, Oryctolagus cuniculus, and their relation to food item in comparison with other animals using scanning and light microscopes.

\section{Materials and Methods}


The observations were conducted on eight tongues of adult rabbit of both sexes. The tongues were dissected from the mandible, fixed in $10 \%$ neutral formaldehyde, and routinely prepared for observation under a scanning electron microscope .The samples of the tongue were dehydrated in a series of ethanol (70-99.8\%) and acetone, then subsequently dried at the critical point using CO2 (Critical Point Dryer K850, Emitech).The specimens were carefully mounted on aluminum stages with double-sided carbon tape, sputtered with $15 \mathrm{~nm}$ thick gold coat (Sputter Coater S 150B,Edwards) and investigated under the Scanning Electron Microscope JEOL (JSM-5400 LV) in Regional Centre of Mycology and Biotechnology, Al-Azhar University, Cairo, Egypt.

Other dissected tongue specimens were fixed in $10 \%$ neutral buffered formalin and routinely prepared as usual for normal histological examinations under light microscope.

\section{RESULTS}

Anatomically, the tongue of the rabbit is of about $45-50 \mathrm{~mm}$ long and $8-9 \mathrm{~mm}$ width. Three regions are distinguished in the dorsal surface of the tongue: the apex (A), the body of the tongue (B) with a well-developed intermolar prominence $(\mathrm{P})$ and root (R) as showed in figure (1). The tip of the tongue is convex and covered with condensed filiform and randomly scattered fungiform papillae (Fig. 2).

The intermolar prominence which is observed in the middle region and called torus lingual or intermolar prominence is covered with special type of filiform papillae (Fig. 3).

By SEM several types of papillae can be seen and designated as filiform, fungiform, foliate and vallate papillae (Figs. 2, 3\& 4 ) in the different regions of the dorsal surface of rabbit tongue.

Filiform papillae occupied the entire dorsal surface and continued to the lateral borders; their size and shape, however varied according to the location. In the torus lingual, filiform papillae looked like a hand with primary papillae and other secondary ones growing from the tip of the primary papillae (Figs. 5, 6). The secondary papillae differ in number ranging between three and five. Near the tongue root on the lateral border of the prominence, pawn chess like filiform papillae with vertical orientation are dispersed (Figs. 7, 8). Tapering filiform papilla with broad base and pending distal ends are seen on the periphery of the intermolar prominence (Figs. 9, 10). Saw shaped filiform papillae with sharp pointed ends cover almost of the dorsal surface of the prominence; these are relatively tighter and taller than the papillae on the anterior part (Figs. 11, 12). Cone shaped filiform papillae caudally pended with concave anterior surface are seen scattered on the tongue root (Figs. 13, 14).

Fungiform papillae are present in the anterior region of the tongue. They were elliptical or circular in shape and embedded in between filiform papillae (Fig. 15). At higher magnification, it is possible to observe dermal papilla contoured by the polygonal cells and keratinized epithelium (Fig. 16).

In the posterior region of the tongue there is a pair of patches loaded with circular vallate papillae, with several taste pores deep depression

inbetween (Fig. 17). In addition numerous taste buds are seen on the side wall of the vallate papilla in-between the slightly keratinized epithelia stratified (Fig. 18).

A pair of well-developed foliate papillae are found in the latero-posterior portion of the tongue, each was oval in shape and had several parallel projections (ridges) separated by shallow grooves and devoid of taste buds and covered by keratinized layer (Figs. 19, 20).

\section{Discussion}

The lingual prominence of the rabbit, present in the caudal area of the tongue, is a characteristic structure of the most grasseating artiodactyls, including cattle, sheep and goats (Tadjali and Pazhoomand, 2004), but is lacking in carnivores and in omnivorous animals such as pigs (Zheng and Kobayashi, 2006).

The filiform papillae are the main mechanical papillae of the rabbit. Each consists of one large main process and several slender accessory processes. These conical papillae participate in transporting and swallowing of food (Adnyane et al., 2011). The filiform papillae in the rabbit are caudally directed, as were those reported in hedgehog by Nasr (2012) and rat by Nasr et al. (2012). So, it can be believed that the presence and distribution of filiform papillae is almost the same in different mammals. However, SEM examination revealed that the filiform papillae of rabbit presented wide morphological variations between different localizations on the tongue surface. This morphological variability together with the direction of bending lead to the assumption that the filiform papillae are involved in directing and facilitating the process of mastication and swallowing of food which was also reported by Son et al. (2000). They suggested that, the bending of filiform papillae toward opposite direction aimed to hold the food until it was swallowed.

Otherwise the fungiform papillae are the most numerous gustatory papillae on the tongue of animals, and their distribution on the apex and body of the tongue is characteristic not only for the rabbit, but also for other animal species (Kulawik and Godynicki, 2007). In the rabbit of the present study the fungiform papillae are more densely distributed among the filiform papillae at the dorsal surface of the tip than the body and the root of the tongue. They were elliptical or circular in shape and are separated from the filiform papillae by a shallow groove, which is similar to the configuration reported in the lamb (Tadjali and Pazhoomand, 2004) and goat (Kurtul and Atalgin, 2008). As in other species of mammals, Jackowiak ( 2006) suggested a protective function for filiform papillae surrounding the fungiform ones. Similar observations were also reported by (Kobayashi et al., 1992) in Tupais glis.

The present study showed the absence of taste buds in the fungiform papillae of the rabbit as reported also in the Reeves' muntjac deer (Zheng and Kobayashi, 2006). Whereas, no taste buds are found in the fungiform papillae of the donkey (Mahmoud et al., 2002), the Egyptian camel (Korany and Bachir, 2004) goat (Kurtul and Atalgin, 2008), hedgehog (Nasr, 2012) and rat (Nasr et al., 2012). Furthermore, the presence of the thick stratified highly keratinized covering layers on the fungiform papillae may give support and protect the lingual papillae against the strong mechanical stress exerted during chewing of rigid food (Mahmoud et al., 2002). This feature is similar to that observed in papillae of the barking deer (Adnyane et al., 2011).

The vallate papillae were the largest lingual papillae in the rabbit. Each of these papillae was surrounded by a continuous deep groove. Their surface

was covered by stratified squamous less keratinized epithelial cells. The taste buds in the vallate papillae of rabbit were numerous and concentrated in the side walls of the papillae, close to the papillary groove. This feature is similar to the configuration observed in Reeves' muntjac deer (Zheng and Kobayashi, 2006). 
The present observations confirmed the characteristics of the foliate papillae reported by (Watanabe et al., 1988) and (Kobayashi, 1992), which presented some parallel projections (ridges) separated by grooves .

\section{References}

Adnyane, I.K.; Zuki1, A.B., Noordin, M. M. and S. Agungpriyono (2011): Morphological study of the lingual papillae in the Barking deer, Muntiacus muntjak. Anat. Histol. Embryol. 40, 73-77.

Chamorro, C.; Fernández, J.; Paz, P.; Pelaez, B. and Anel, L. (1994): Scanning Electron Microscopy of the wild boar and pig lingual papillae. Histol. Histopathol. Oct., 9 (4), 657-67.

Chamorro, C.; Sandoval, J.; Fernandez, J.; Fernandez, M. and Paz, P. (1987): Comparative studies of lingual papillae of cat (Felis catus) and rabbit (Oryctolagus cuniculus) by Scanning Electron Microscopy .Anat. Histol. Embryol.16, 37-47.

Davis, D.D. (1964): The giant panda: a morphological study of evolutionary mechanism . Fieldiana Zoolology Memoirs, 3, 1339.

Emura, S.; Tamada, A.; Hayakawa, D.; Chen, H. and Shoumura, S.(2000a): Morphology of the dorsal lingual papillae in the black rhinoceros (Dicerosbicornis) Anat. Histol. Embryol. 29 (6), 371-374.

Emura, S.; Tamada, A.; Hayakawa, D.; Chen, H. and Shoumura, S. (2000b): Morphology of the dorsal lingual papillae in the barbary sheep, Ammotragu lervia. Okajimas Folia Anat. Jpn.77, 39-45.

Emura, S.; Hayakawa, D.; Chen, H. and Shoumura, S. (2004): Morphology of the lingual papillae in the tiger. Okajimas Folia Anat. Jpn. 81, 39-44.

Holland, V.F.; Zampighi, G.A. and Simon, S.A. (1989): Morphology of fungiform papillae in canine lingual epithelium: location of intercellular junctions in the epithelium. J. Comp. Neurol. 279, 13-27

Iida, M.; Yoshioka, I. and Muto, H. (1985): Three-dimensional and surfaces structures of rat filiform papillae. Acta. Anat. 121, 237-244.

Iwasaki, S. (2002): Evolution of the structure and function of the vertebrate tongue. J. Anat. 201, 1-13.

Iwasaki, S.; Yoshizawa, H. and Suzuki, K. (1992): Fine structure of the dorsal lingual epithelium of the japanese monkey Macaca fuscata fuscata .Acta. Anat. 144, 267-277.

Jackowiak, H.,( 2006): Scanning Electron Microscopy study of the lingual papillae in the European Mole (Talpa europea,L., Talpidae). Anat. Histol. Embryol., 35, 190-195

Kobayashi, K. (1992): Stereo architecture of the interface of the epithelial cell layer and connective tissue core of the foliate papilla in the rabbit tongue. Acta. Anat. 143, 109-117.

Koeing, H.E. and Liebig, H.G. (2001): Anatomie und Propadeutik des Geflugels. Lehrbuch and Farbatlas fur Studium und Praxis. Schattauer Stuttgart, NY

Korany, N.S. and Bachir, M.H.( 2004): Morphofunctional study of different tongue papillae in ruminants and rodentia. a) Scanning Electron Microscopic and histological studies. Cairo Dental J.20 (2), 215-220

Kulawik, M. and Godynicki, S. (2007): Fungiform papillae of the tongue in the rabbit (Oryctolagus cuniculus). Polish J. Vet. Sci., 10 (1), 25-27
Kurtul, I., and Atalgin, S.H. (2008): Scanning Electron Microscopic study on the structure of the lingual papillae of the Saanen goat. Small Rumin. Res. 80, 52-56.

Mahmoud, M.; Abd-Elnaeim, M.; Zayed, A.E. and Leiser, R. (2002): Morphological characteristics of the tongue and its papillae in the donkey (Equusasinus): a light and scanning electron microscopical study. Ann. Anat. 184, 473-480.

Nasr, E.S. (2012): Surface morphological structure of the tongue of the hedgehog, Hemiechinus auritus (Insectivora: Erinaceidae) J. Am. Sci. 8(4), 580-588.

Nasr, E.S; Gamal, A.M.; Elsheikh, E.H.(2012): Light and scanning electron microscopic study of the dorsal lingual papillae of the rat, Arvicanthis niloticus (Muridae, Rodentia). J. Am. Sci. 8(4), 619-627.

Paz, P.; Chamorro, C.A.; Sandoval, J. and Ferndndez, M. (1988): Comparative scanning electron-microscopic study of the lingual papillae in two species of domestic mammals. (Equuscaballus and Bostaurus). II. Mechanical papillae. Acta. Anat. 132, 120-123.

Roth, G. and Wake, D.B. (1989): Conservatism and innovation in the evolution of feeding in vertebrates. Complex Organismal Function: Integration and Evolution in Vertebrates. (eds. Wake, D.B.; Roth G.), pp.7-21. New John Wiley \& Sons.

Son, S.W.; Lee, H.J. and Lee, J.H. (2000): Ultrastructural observations of the lingual papillae of the Korean greater horseshoe bat, Rhinolophus ferrumequinum korai. Kyungnam Univ. J. Basic Sci. Res. Int., 14 ,65 -72.

Sonntag, C.F. (1923) :The comparative anatomy of the tongues of the mammalia. VIII. Carnivora. Proc. Zoo . Soc. Lond. IX, $129-152$.

Tadjali, M., and Pazhoomand, R. (2004): Tongue papilla in lambs: a Scanning Electron Microscopic study. Small Rumin. Res. $54,157-164$.

Watanabe, I.; Ogawa, K. and Yamada, E. (1988): Taste buds of the rabbit foliate papillae. A scanning electron microscopy study. Ciênc. Cult. 40, 787-790.

Zheng, J., and K. Kobayashi, (2006): Comparative morphological study on the lingual papillae and their connective tissue cores (CTC) in Reeves' muntjac deer (Muntiacu sreevesi). Ann. Anat. 188, 555-564. 
Fig.(4) Scanning electron micrograph in root tongue of the Rabbit, showing Vallate (V) and Foliate (FO) papillae. Scale bar $=200 \mu$.

Fig.(5-6) SEM and LM. in torus lingual showing type of Filiform papillae with secondary

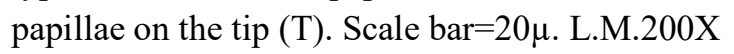

Fig.(7-8) SEM and LM. in lateral border of intermolar prominence showing Filiform papillae with vertical orientation (Fi). Scale bar $=100 \mu$. L.M.200X.
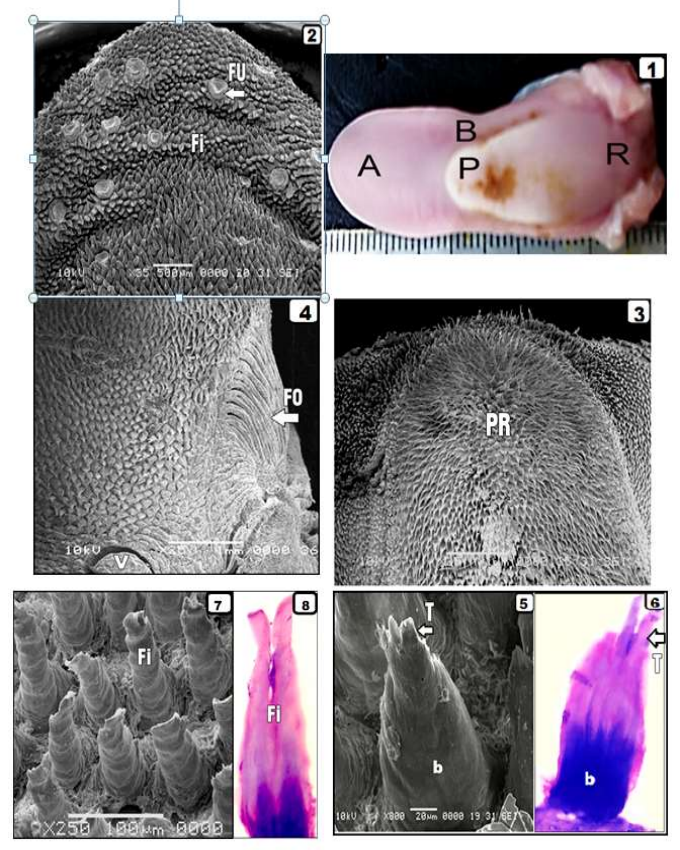

Fig.(1) Gross anatomy of the tongue Rabbit, showing its different regions the apex (A), well developed prominence $(\mathrm{P})$, and $\operatorname{root}(\mathrm{R})$.

Fig.(2) Scanning electron micrograph of the tip tongue Rabbit, showing Filiform (Fi) and randomly scattered Fungiform papillae (FU).Scale bar $=500 \mu$.

Fig.(3) Scanning electron micrograph of the intermolar prominence (PR) in tongue Rabbit, showing special type of Filiform papillae Scale bar $=250 \mu$.

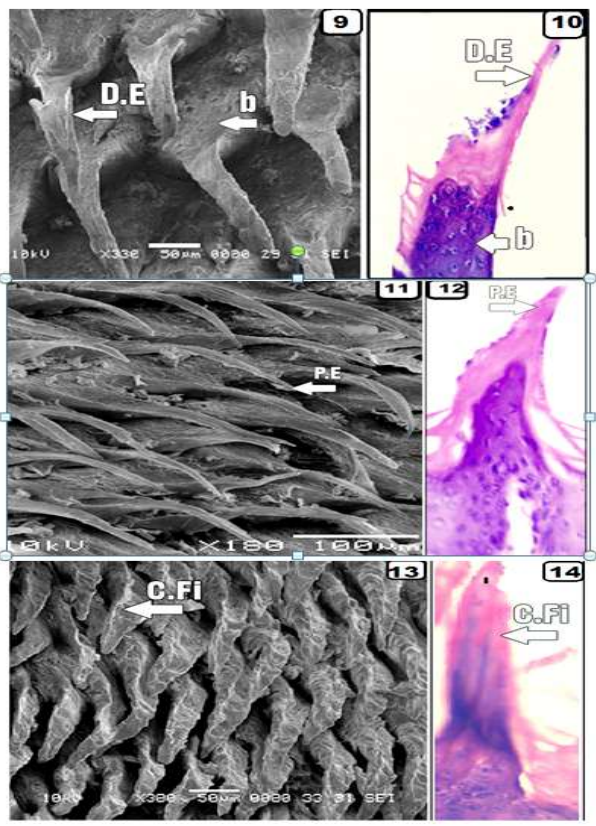

Fig.(9-10) SEM and LM. in periphery of the intermolar prominence showing Filiform papillae with broad base (b) and pending distal end (DE). Scale bar=50 .L.M.200X

Fig.(11-12) SEM and LM. in the dorsal surface of the intermolar prominence showing the relatively tighter and taller filiform papillae with sharp pointed end (PE).Scale bar $=100 \mu$. L.M.200X 
Fig.(13-14) SEM and LM. in tongue root showing von shape Filiform papillae (C.FI). Scale bar $=50 \mu$. L.M.200X

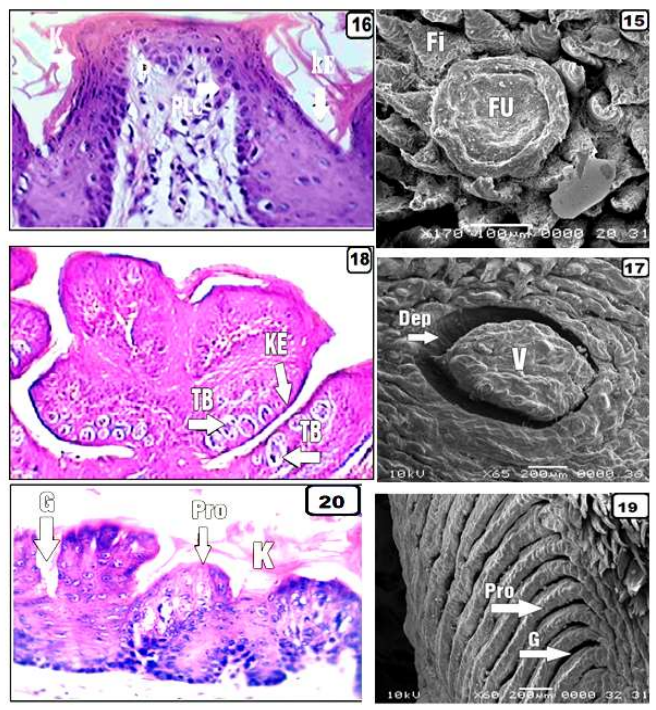

Fig.(15) SEM in the anterior region of the tongue Fungiform papillae (FU) embedded in between Filiform papillae (Fi). Scale bar $=100 \mu$.

Fig.(16) LM. in the Fungiform papillae showing contour of polygonal cells (PLC), keratinized epithelia (KE),dermal papilla(P) and keratinized layer (K).200X

Fig.(17) SEM in the posterior region of the tongue to showing circular Vallate papillae (V) with continues deep depression (Dep). Scale bar $=200 \mu$.
Fig.(18) LM. in Vallate papillae showing several taste pores and taste buds (TB) between slightly keratinized epithelia (KE).200X

Fig.(19-20) SEM and LM. in latero-posterior portion of the tongue showing the Foliate papilla with oval shape had several parallel projection (Pro) separated by shallow grooves (G) and devoid of taste buds and covred by keratinized layer (K) Scale bar $=200 \mu$. L.M.200X. 